\title{
Low ALT Levels Associated with Poor Outcomes in 8700 Hospitalized Heart Failure Patients
}

\author{
Amitai Segev 1,+(i), Edward Itelman ${ }^{1,+}$, Chen Avaky ${ }^{1}$, Liat Negru ${ }^{1}$, Gilat Shenhav-Saltzman ${ }^{1}$, \\ Avishay Grupper ${ }^{2}$, Yishay Wasserstrum ${ }^{1}$ and Gad Segal ${ }^{1, *(D)}$ \\ 1 Internal Medicine "T", Chaim Sheba Medical Center, Sackler Faculty of Medicine, Tel-Aviv University, \\ Ramat-Gan 5266202, Israel; agsegev@yahoo.com (A.S.); edi.itelman@gmail.com (E.I.); \\ chenavaky@gmail.com (C.A.); liatneg@gmail.com (L.N.); gilatshenhav@gmail.com (G.S.-S.); \\ yishay.wasserstrum@gmail.com (Y.W.) \\ 2 Cardiovascular Division, Chaim Sheba Medical Center, Sackler Faculty of Medicine, Tel-Aviv University, \\ Ramat-Gan 5266202, Israel; avishay.grupper@sheba.health.gov.il \\ * Correspondence: gad.segal@sheba.health.gov.il; Tel.: +972-(52)-666-95-80 \\ + Authors with equal contribution.
}

Received: 27 August 2020; Accepted: 28 September 2020; Published: 30 September 2020

\begin{abstract}
Sarcopenia and frailty are causes for morbidity and mortality amongst heart failure (HF) patients. Low alanine transaminase (ALT) is a marker for these syndromes and, therefore, could serve as a biomarker for the prognostication of HF patients. We performed a retrospective analysis of all consecutive hospitalized HF patients in our institute in order to find out whether low ALT values would be a biomarker for poor outcomes. Our cohort included 11,102 patients, $35.6 \%$ categorized as heart failure with reduced ejection fraction. We excluded patients with ALT $>40 \mathrm{IU} / \mathrm{L}$ and cirrhosis. 8700 patients were followed for a median duration of 22 months and included in a univariate analysis. Patients with ALT $<10 \mathrm{IU} / \mathrm{L}$ were older (mean age 78.6 vs. $81.8, p<0.001)$, had past stroke $(24.6 \%$ vs. $19.6 \%, p<0.001)$, dementia ( $7.7 \%$ vs. $4.6 \%, p<0.001)$, and malignancy $(13.4 \%$ vs. $10.2 \%, p=0.003)$. Hospitalization length was longer in the low-ALT group (4 vs. 3 days, $p<0.001$ ), and the rate of acute kidney injury during hospitalization was higher (19.1\% vs. $15.6 \% ; p=0.006)$. The in-hospital mortality rate was higher in the low-ALT group $(6.5 \%$ vs. $3.9 \% ; p<0.001)$. Long-term mortality was also higher $(73.3 \%$ vs. $61.5 \%$; $p<0.001)$. In a multivariate regression analysis, ALT $<10 \mathrm{IU} / \mathrm{L}$ had a 1.22 hazard ratio for mortality throughout the follow-up period $(\mathrm{CI}=1.09-1.36 ; p<0.001)$. Low ALT plasma level, a biomarker for sarcopenia and frailty, can assist clinicians in prognostic stratification of heart failure patients.
\end{abstract}

Keywords: heart failure; sarcopenia; frailty; ALT; prognosis

\section{Introduction}

Heart failure (HF), either with reduced ejection fraction (HFrEF) or preserved ejection fraction (HFpEF), remains a rising global epidemic and a major cause of re-hospitalizations, increased overall (both short- and long-term) mortality, limited exercise capacity, and significantly lower quality of life [1-4]. Frailty is a clinical syndrome manifesting as increased vulnerability from age-related decline in physiological reserve and function, leading to a reduced ability to tolerate biological stressors. Operationally, Fried et al. defined frailty as fulfilling three or more of the following criteria of reduced gait speed, reduced grip strength, exhaustion, unintended loss of body weight, and lowered physical activity [5]. Frailty is the phenotypic entity resulting from sarcopenia. Both sarcopenia and frailty are increasingly being recognized as significant contributors of morbidity and mortality, not only amongst the most elderly but also in mid-life patients [6,7]. Approximately $25 \%$ of older patients with HF 
exhibit evidence of frailty [8,9], increasingly recognized as a well-established predictor of negative clinical outcomes in such patients [10-13]. A long-term search for available biomarkers of sarcopenia and frailty is still ongoing, both for the general population of frail patients and those with both frailty and heart failure.

Alanine transaminase (ALT) serves in many tissues to facilitate the conversion of pyruvate to the amino acid alanine. As such, it helps to reuse potentially "dead-end" carbohydrates within skeletal muscle tissue, after re-conversion of alanine to pyruvate within the liver. The most common use for ALT measurements has long been for monitoring liver tissue damage. Nevertheless, when the liver parenchyma is intact, ALT blood levels (demonstrated as catalytic activity) are a good marker for the whole-body skeletal muscle mass $[14,15]$. Utilizing the aforementioned, a large body of evidence accumulated in the past years, marking lower ALT values as a reliable marker for sarcopenia and frailty, in large, heterogeneous patient populations [16-19]. Characterizing sarcopenia and frailty status in patients with HF may provide clinicians with an indicator for gauging disease severity, prognosis, and disease progression or reversal. The role of plasma ALT activity in HF patients has not been described thus far.

\section{Materials and Methods}

We performed a retrospective analysis of all consecutive patients admitted between 1/3/2007 and 31/1/2020 at Chaim Sheba Medical Center, the largest tertiary hospital in Israel, with a main diagnosis of HF or a related ICD-10 code. Patients or the public were not involved in the design, conduct, reporting, or dissemination plans of our research. Excluded from the study were patients with plasma ALT activity above normal ( $>40 \mathrm{IU} / \mathrm{L}$ ) and patients with a diagnosis of cirrhosis at baseline, since it is assumed that their ALT blood level does not reflect the total muscle mass and might be derived from damaged liver tissue as well. Exclusion of such patients was the rule in all other, previous ALT-associated sarcopenia and frailty studies [14,17,20-24]. We retrieved patients' data from their electronic medical records after study approval by the local institutional review board.

We collected all relevant medical history and background diagnoses from the coded electronic patient chart. Congestive-HF-related admissions were considered as readmissions with a main diagnosis of HF or other related ICD-10 codes, at our institution. Laboratory data were taken from the first available laboratory tests within the index hospitalization. We defined acute kidney injury (AKI) as an increase in serum creatinine by $\geq 0.3 \mathrm{mg} / \mathrm{dL}$ or an increase to $\geq 1.5$ times the baseline value upon admission. Echocardiography data were retrieved from the most recent exam available within 6 months before or after the index hospitalization $(90 \%$ of the exams were performed between 13 days prior to and 12 days after the index hospitalization). Mortality data were extracted from the Israeli National Population Register and were available for all cases. Patients were stratified into two groups based on their first ALT measurement within the index hospitalization: low-normal ALT group (ALT < $10 \mathrm{IU} / \mathrm{L}$ ) vs. high-normal ALT group (ALT $\geq 10 \mathrm{IU} / \mathrm{L}$ ). We adopted the cutoff value of $10 \mathrm{IU} / \mathrm{L}$ from previous research in this field $[20,21,24]$. We compared clinical, laboratory, and echocardiographic parameters between these groups.

\section{Statistical Analysis}

We described variables according to their properties. Categorical variables are reported in frequencies and percentages, and significance was assessed using the chi-square test or Fischer's exact test when appropriate. Continuous variables with a normal distribution were reported as mean and standard deviation values, and significance was assessed using the Student's t-test. Continuous variables that did not have a normal distribution were reported as median and interquartile range (IQR, 25th-75th percentiles) values, and significance was assessed using the Mann-Whitney U test. All statistical tests were two-sided, and a $p$-value of less than 0.05 was considered significant. We constructed a Cox regression model with the following variables to control for properties contributing to mortality: age, gender, history of cerebrovascular disease (defined as previous stroke or transient 
ischemic attack), history of diabetes mellitus (DM), history of ischemic heart disease (IHD), hemoglobin levels, creatinine clearance (estimated by the MDRD formula), albumin levels, left ventricular ejection fraction (LVEF), and severe right ventricular (RV) dysfunction. We used follow-up time and death as the event recorded. We constructed a forest plot according to the above model results. We used a Kaplan-Meier curve for survival, with death as the accumulating event for a follow-up time of up to 5 years. The statistical analysis was carried out with the use of $R$ version 3.6.1 software (The $R$ Foundation) and PyCharm community edition, V2020.1.1 (JetBrains).

\section{Results}

\subsection{Patient Characteristics}

The study cohort consisted of 11,102 patients who were admitted at our medical center with a main diagnosis of HF exacerbation. Figure 1 shows the total patient cohort flow and exclusions. 8700 patients (55\% males) were followed for a median duration of $22(6-49)$ months and were eligible for inclusion in a univariate analysis. Out of these, $35.6 \%$ of patients were categorized as HFrEF. The cohort population manifests a high comorbidity rate $(70 \%$ hypertension, $49 \%$ ischemic heart disease, $42 \%$ diabetes, $41 \%$ atrial fibrillation, $19 \%$ chronic kidney disease, $16 \%$ chronic obstructive pulmonary disease (COPD), and $14 \%$ solid or hematologic malignancy). Table 1 shows the patients' characteristics according to their ALT activity level in the blood. Patients with ALT lower than $10 \mathrm{IU} / \mathrm{L}$ were older (mean age 78.6 vs. 81.8 years, $p<0.001$ ), had a history of cerebrovascular disease (defined as previous stroke or transient ischemic attack; $24.6 \%$ vs. $19.6 \%, p<0.001$ ), suffered more often from dementia (7.7\% vs. $4.6 \%, p<0.001)$, and had a higher incidence of malignancy ( $13.4 \%$ vs. $10.2 \%, p=0.003)$. Regarding baseline laboratory parameters, patients in the low-ALT group had lower hemoglobin concentration (10.6 vs. $11.5 \mathrm{~g} / \mathrm{dL}, p<0.001)$, worse renal function according to the MDRD values (43.2 vs. $51.5 \mathrm{~mL} / \mathrm{min} / 1.73 \mathrm{~m}^{2}, p<0.001$ ) and a lower albumin concentration ( 3.4 vs. $\left.3.6 \mathrm{~g} / \mathrm{dL}, p<0.001\right)$. HF patients with lower ALT values had better systolic cardiac function as reflected in their left ventricular ejection fraction (LVEF) values ( $55 \%$ vs. $50 \%, p=0.006$ ). Other echocardiographic parameters did not differ between the groups, including systolic pulmonary artery pressure (SPAP), the presence of mitral or tricuspid regurgitation, and right ventricular (RV) size and function.

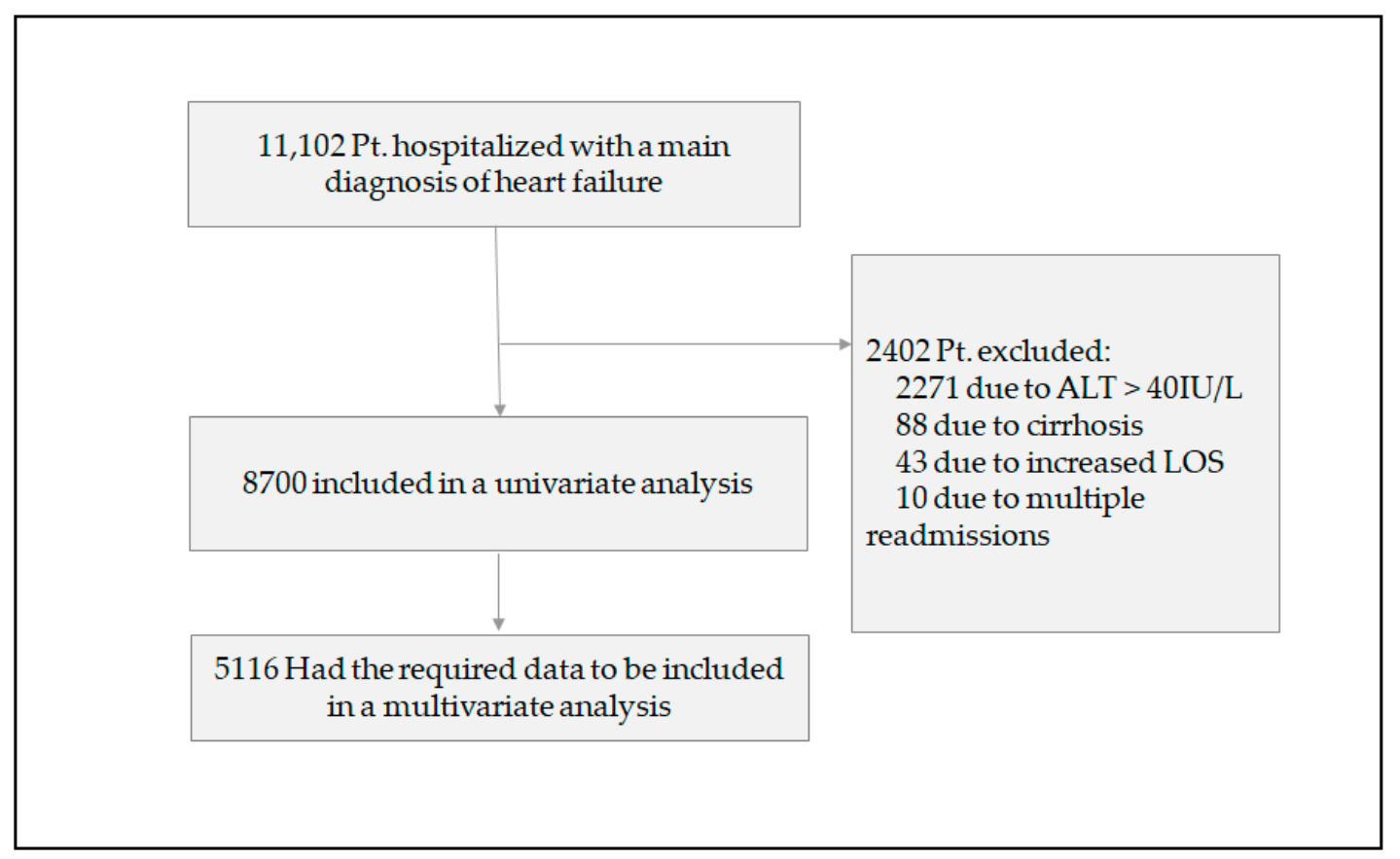

Figure 1. Flow and exclusions in the whole study cohort. LOS = length of (hospital) stay. 
Table 1. Patients' characteristics according to their baseline alanine transaminase (ALT) blood activity level.

\begin{tabular}{|c|c|c|c|c|}
\hline & $\begin{aligned} & \mathrm{ALT} \geq 10 \mathrm{IU} / \mathrm{L} \\
&(\mathrm{n}=7742)\end{aligned}$ & $\begin{array}{c}\mathrm{ALT}<10 \mathrm{IU} / \mathrm{L} \\
(\mathrm{n}=958)\end{array}$ & $\begin{array}{c}\text { Total } \\
(\mathrm{n}=8700)\end{array}$ & $p$-Value \\
\hline \multicolumn{5}{|c|}{ Patients' demographics } \\
\hline Age-years, median (IQR) & $78.6(69.4-85.6)$ & $81.8(72.7-87.5)$ & $\begin{array}{c}79 \\
(69.8-85.8)\end{array}$ & $<0.001$ \\
\hline Male gender-number (\%) & $4365(56.4)$ & $467(48.7)$ & $4832(55.5)$ & $<0.001$ \\
\hline \multicolumn{5}{|c|}{ Comorbidities number (\%) } \\
\hline HTN & $5358(69.2)$ & $686(71.6)$ & $6044(69.5)$ & 0.138 \\
\hline $\mathrm{DM}$ & $3259(42.1)$ & $416(43.4)$ & $3675(42.2)$ & 0.453 \\
\hline Dyslipidemia & $1842(23.8)$ & $200(20.9)$ & $2042(23.5)$ & 0.049 \\
\hline IHD & 3789 (48.9) & $445(47.6)$ & $4245(48.8)$ & 0.454 \\
\hline Cerebrovascular disease & 1517 (19.6) & $236(24.6)$ & $1753(20.1)$ & $<0.001$ \\
\hline Atrial fibrillation & $3237(41.8)$ & $376(39.2)$ & $3613(41.5)$ & 0.138 \\
\hline Dementia & $354(4.6)$ & $74(7.7)$ & $428(4.9)$ & $<0.001$ \\
\hline COPD & $1272(16.4)$ & $170(17.7)$ & $1442(16.6)$ & 0.324 \\
\hline Solid malignancy & $786(10.2)$ & $128(13.4)$ & $914(10.5)$ & 0.003 \\
\hline Hematologic malignancy & $256(3.3)$ & $32(3.3)$ & $288(3.3)$ & $>0.99$ \\
\hline CKD & 1446 (18.7) & $197(20.6)$ & $1643(18.9)$ & 0.173 \\
\hline \multicolumn{5}{|c|}{ Baseline laboratory parameters median (IQR) } \\
\hline ALT (IU/L) & $18(14-25)$ & $8(7-9)$ & $17(12-24)$ & $<0.001$ \\
\hline Hemoglobin (g/dL) & $11.5(10.1-12.9)$ & $10.6(9.3-11.8)$ & $\begin{array}{c}11.4 \\
(10-12.8)\end{array}$ & $<0.001$ \\
\hline Creatinine $(\mathrm{mg} / \mathrm{dL})$ & $1.2(0.9-1.6)$ & $1.3(1-1.9)$ & $1.2(0.9-1.6)$ & $<0.001$ \\
\hline $\operatorname{MDRD}\left(\mathrm{mL} / \mathrm{min} / 1.73 \mathrm{~m}^{2}\right)$ & $51.5(35.7-69.1)$ & $43.2(28.8-63.4)$ & $\begin{array}{c}50.6 \\
(34.8-68.5)\end{array}$ & $<0.001$ \\
\hline $\operatorname{Albumin}(\mathrm{g} / \mathrm{dL})$ & $3.6(3.3-3.9)$ & $3.4(3.1-3.7)$ & $3.6(3.2-3.9)$ & $<0.001$ \\
\hline \multicolumn{5}{|c|}{ Echocardiography findings } \\
\hline LVEF \%, median (IQR) & $50(30-60)$ & $55(35-60)$ & $50(30-60)$ & 0.006 \\
\hline $\mathrm{MR}-\mathrm{n}(\%)$ & & & & 0.503 \\
\hline None & $437(9.5)$ & $47(8.5)$ & \multicolumn{2}{|c|}{$484(9.4)$} \\
\hline Moderate & $508(11.0)$ & $48(8.6)$ & \multicolumn{2}{|c|}{$556(10.7)$} \\
\hline Severe & $222(4.8)$ & $23(4.1)$ & \multicolumn{2}{|c|}{$245(4.7)$} \\
\hline $\mathrm{TR}-\mathrm{n}(\%)$ & & & & 0.421 \\
\hline None & $260(5.6)$ & $36(6.5)$ & \multicolumn{2}{|c|}{$296(5.7)$} \\
\hline Moderate & $553(12.0)$ & $66(11.9)$ & \multicolumn{2}{|c|}{$619(12.0)$} \\
\hline Severe & $307(6.6)$ & $47(8.5)$ & \multicolumn{2}{|c|}{$354(6.8)$} \\
\hline \multicolumn{3}{|c|}{$\mathrm{RVF}-\mathrm{n}(\%)$} & & 0.81 \\
\hline Normal & $3420(74.0)$ & $421(75.9)$ & \multicolumn{2}{|c|}{$3841(74.2)$} \\
\hline Severely reduced & $249(5.4)$ & $28(5.0)$ & \multicolumn{2}{|c|}{$277(5.4)$} \\
\hline Dilated RV & $1028(22.3)$ & $130(23.4)$ & $1158(22.4)$ & 0.576 \\
\hline
\end{tabular}

$\mathrm{IQR}=$ interquartile range; $\mathrm{HTN}$ = hypertension; $\mathrm{DM}$ = diabetes mellitus; $\mathrm{IHD}=$ ischemic heart disease; $\mathrm{COPD}=$ chronic obstructive pulmonary disease; $\mathrm{CKD}=$ chronic kidney disease; $\mathrm{LVEF}=$ left ventricular ejection fraction; $\mathrm{SPAP}=$ systolic pulmonary artery pressure; $\mathrm{MR}=$ mitral regurgitation; $\mathrm{TR}=$ tricuspid regurgitation; $\mathrm{LVEDD}=$ left ventricular end diastolic diameter; $\mathrm{RVF}=$ right ventricular function; $\mathrm{HFrEF}=$ heart failure with reduced ejection fraction. Values in bold are statistically significant. 


\subsection{Short- and Long-Term Outcomes}

Hospitalization length was longer in the low-ALT group compared to that in the high-ALT group ( 4 vs. 3 days, $p<0.001$ ), and the rate of acute kidney injury (AKI) was significantly higher in HF patients with low ALT values $(19.1 \%$ vs. $15.6 \% ; p=0.006)$ (Table 2$)$. Mortality rate within the index hospitalization was higher in the low-ALT group compared to that in the high-ALT group $(6.5 \% \mathrm{vs}$. $3.9 \% ; p<0.001)$. Long-term mortality was also significantly higher in the low-ALT group $(73.3 \%$ vs. $61.5 \% ; p<0.001$ ) (Figure 2). Hospital readmission rate, both total and HF related, did not differ between the two groups.

Table 2. Short-and long-term outcomes.

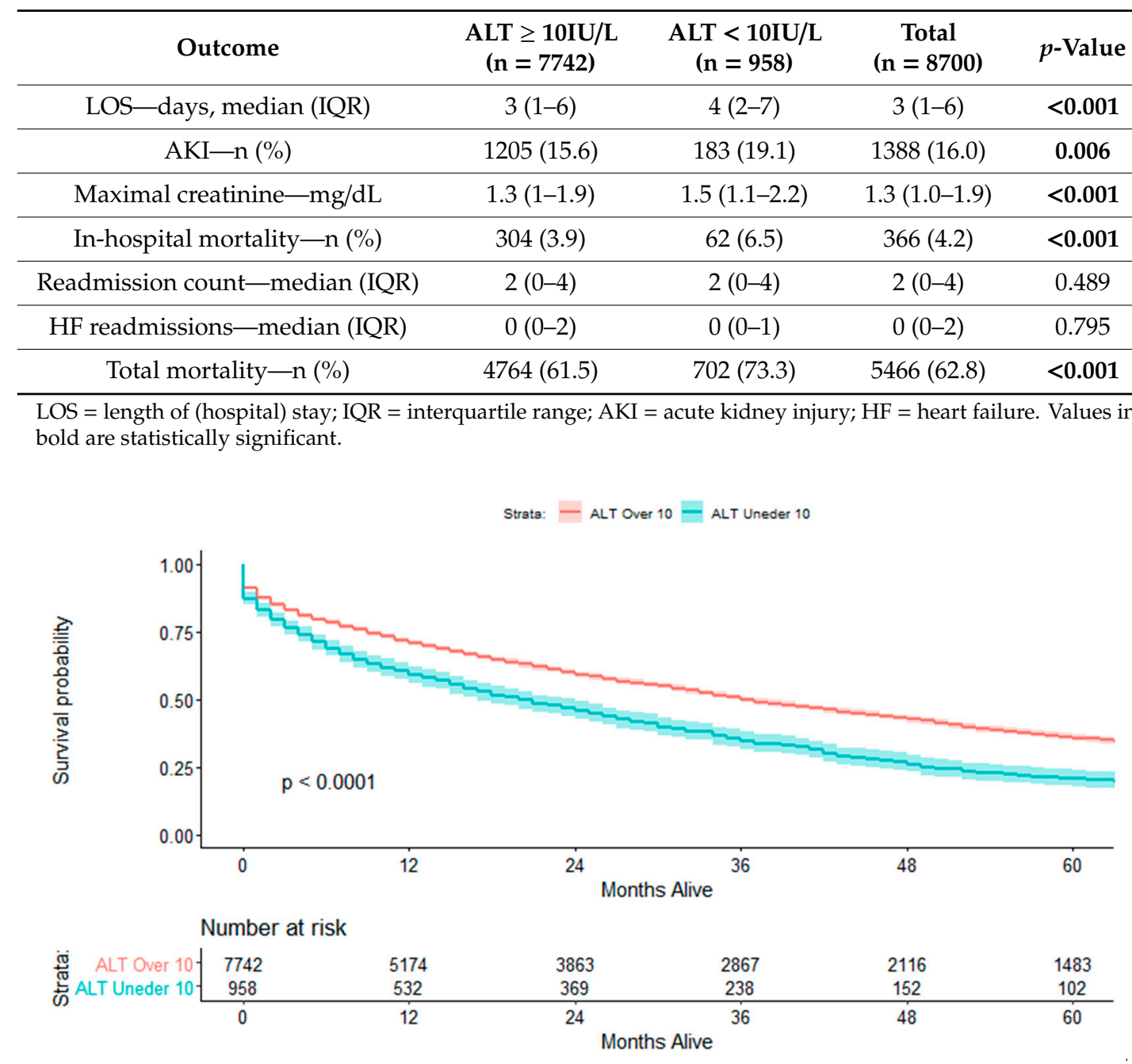

Figure 2. Survival according to baseline ALT level.

\subsection{Multivariate Analysis}

We performed a multivariate regression model analysis showing that after factoring in clinically important parameters, ALT below $10 \mathrm{IU} / \mathrm{L}$ had a 1.22 hazard ratio (HR) for mortality throughout the follow-up period (confidence interval (CI) 1.09-1.36; $p<0.001$ ) (Figure 3). 


\begin{tabular}{|c|c|c|c|c|c|}
\hline Variable & $\mathbf{N}$ & Haz & card ratio & & $\mathrm{p}$ \\
\hline Age & 5116 & & - & $1.04(1.04,1.04)$ & $<0.001$ \\
\hline Male gender & 5116 & & $\longmapsto$ & $1.09(1.01,1.18)$ & 0.029 \\
\hline Cerebrovascular disease & 5116 & & $\longmapsto$ & $1.11(1.02,1.22)$ & 0.017 \\
\hline DM & 5116 & & $\longmapsto$ & $1.13(1.05,1.22)$ & 0.001 \\
\hline IHD & 5116 & & $\longrightarrow$ & $1.06(0.98,1.15)$ & 0.120 \\
\hline $\mathrm{Hb}$ & 5116 & - & & $0.96(0.95,0.98)$ & $<0.001$ \\
\hline MDRD & 5116 & 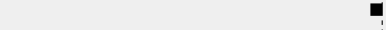 & & $0.99(0.99,0.99)$ & $<0.001$ \\
\hline Albumin & 5116 & $\longmapsto$ & & $0.56(0.52,0.60)$ & $<0.001$ \\
\hline LVEF & 5116 & a & & $0.99(0.99,0.99)$ & $<0.001$ \\
\hline Severe RV Dysfunction & 5116 & & $\longmapsto$ & $1.80(1.55,2.10)$ & $<0.001$ \\
\hline ALT $T<10$ & 5116 & & $\longmapsto$ & $1.22(1.09,1.36)$ & $<0.001$ \\
\hline
\end{tabular}

Figure 3. Forest plot depicting multivariate analysis for mortality.

\section{Discussion}

This is the first study, thus far, to our knowledge, to evaluate the clinical utility of ALT plasma activity as an independent prognostic factor in hospitalized HF patients. In our study, low ALT plasma activity was associated with longer hospitalization stay, increased rates of kidney injury during the index hospitalization, and increased mortality, both in-hospital and long-term. A multivariate model further demonstrated the strong independent association between low ALT and mortality, sustained even after including other clinically important baseline comorbidities.

HF remains an important cause for morbidity and mortality, especially in the elderly. Whereas the prevalence of HF is approximately $1-2 \%$ of the adult population in developed countries, it rises to over $10 \%$ among people 70 years of age or older. The hospitalization and mortality rate in HF patients is extremely high. In the European ESC-HF pilot study, the 12-month rates in hospitalized HF patients were $44 \%$ and $17 \%$, respectively [25].

Frailty is increasingly recognized as an important target for monitoring and intervention in contemporary cardiovascular care and management [26,27]. The role of frailty assessment in management decision-making and for the determination of procedural eligibility has been previously shown to affect patient outcomes and provide prognostic indication of well-being and survival associated with procedures, ranging from transcatheter and surgical aortic valve replacement to heart transplantation [27-29]. In HF patients, frailty is not only very common, reaching over $70 \%$ in patients 80 years of age or older [30], but also is an important prognostic factor. A 2018 systematic review of 14 studies including over 5000 chronic HF patients showed an association between frailty and increased risk for mortality $(\mathrm{HR}=1.54 ; 95 \% \mathrm{CI} 1.34-1.75 ; p<0.001)$ and incident hospitalization $(\mathrm{HR}=$ $1.56 ; 95 \%$ CI 1.36-1.78; $p<0.001$ ] [31]. Frailty is associated with circulating inflammatory cytokines and sarcopenia, features that are shared with HF [32]. DNA damage, impaired autophagy, and mitochondrial dysfunction occur in both aging and HF and can lead to metabolic dysfunction, cellular senescence, and ultimately cellular necrosis, in turn leading to the activation of innate immunity and production and secretion of inflammatory mediators into the circulation. The subsequent inflammation could, on the one hand, lead to frailty and could also negatively affect myocardial function via the negative inotropic effects of the circulating cytokines [33]. Systemic inflammation can also accelerate skeletal muscle apoptosis and promote sarcopenia [34], that could enhance immobility and cachexia associated with both HF and frailty.

The consensus regarding the importance of frailty assessment amongst HF patients only necessitates an available and reliable biomarker. Conventional assessment of frailty is done using frailty scoring systems, including walking speed (gait speed test), timed up-and-go test, PRISMA 7 questionnaire, Frail Score, Fried Score, and Short Physical Performance Battery (SPPB) $[5,35,36]$.

Serum ALT is a readily available, inexpensive, and routine biochemical assay used in clinical practice. A large number of studies have established the association between low ALT levels and 
sarcopenia and frailty in both middle-aged [22] and elderly patients [16,37] and in a myriad of clinical contexts $[18,19]$. A prospective study of 179 patients in an internal ward found that low ALT blood activity and high Frail questionnaire score correlated with increased mortality and with each other [17]. Another study showed that an ALT > 10 IU/L among elderly patients with hip fracture was associated with better functional and cognitive status, as shown by higher total FIM (Functional Independence Measure) scores, cognitive FIM scores $(>16)$, and FIM efficiency $(>0.228)$ in a logistic regression analysis adjusted for age and gender $(\mathrm{OR}=1.56-1.78)$ [24]. In clinical cardiology, low ALT levels were associated with increased long-term mortality among 6575 middle-aged patients with stable coronary heart disease [38], increased 90-day mortality in 6264 patients undergoing cardiovascular surgery [39], and lower baseline fitness and poor rehabilitation outcomes amongst 3806 participants of a cardiac rehabilitation program [23]. As opposed to the conventional assessment of frailty, ALT plasma measurement does not require additional substantial resources such as work force, money, and time.

In our study, we aimed to establish the association between low ALT levels and poor clinical outcomes in HF patients. To increase clinical utility, we selected the hospital admission as the point in time to evaluate the ALT level. In order to avoid potential bias after admission (e.g., prescribed medications affecting liver enzymes), we collected ALT levels upon admission. Abnormally high ALT levels (i.e., above $40 \mathrm{IU} / \mathrm{L}$ ) might derive from damaged liver tissue and do not necessarily reflect the total body muscle mass and, therefore, cannot serve as a reliable marker for sarcopenia and frailty. Nevertheless, high ALT levels, as a marker of hypoperfusion and liver tissue damage, were previously found to be independently associated with increased mortality in HF patients [40].

In our study, patients in the low-ALT group had a higher rate of cerebrovascular disease, dementia, and malignancy at baseline. As these patients are less mobile, less robust, and more frail, they succumb to sarcopenia and are expected to have lower ALT blood levels. In addition, despite having higher LVEF at baseline, the low-ALT group demonstrated increased mortality. We believe that this observation further strengthens the association between low ALT and poor outcomes in HF patients, as manifested by better mortality prediction in a multivariate regression model (see Section 3.3. Multivariate Analysis).

Currently, frailty is not routinely assessed for or systematically categorized in patients with HF [41-43]. However, in our study, we found a strong association between low ALT levels and poor clinical outcomes, both short- and long-term, in a large cohort of hospitalized HF patients. This association, sustained after inclusion of other important prognostic markers, may be of great clinical importance.

\section{Limitations}

We acknowledge some limitations to our study. First, this was an observational study with a retrospective analysis of collected data. Second, the study was conducted in a single tertiary medical center and there may have been patient selection bias. Thus, the data cannot necessarily be extrapolated to other centers. In addition, as in many studies, we relied on digitally encrypted events such as coded background diagnoses. Lastly, readmissions were considered in our center alone.

\section{Conclusions}

Our findings may significantly improve current clinical practices regarding heart failure patients. We believe the findings from our study should encourage the use of frailty assessment for risk stratification of patients with HF in order to inform prognosis and management decisions. We hereby suggest a novel, easy to measure, and cheap biomarker for frailty assessment in HF patients.

We believe that simple ALT measurement may be the first, small step, in the very long journey toward personalized medicine. 
Author Contributions: Conceptualization, A.S., E.I., C.A., L.N., G.S.-S., A.G. and G.S.; data curation, A.S. and E.I.; formal analysis, A.S., E.I., Y.W. and G.S.; methodology, A.S., E.I., A.G., Y.W. and G.S.; writing—original draft, A.S., E.I., A.G., Y.W. and G.S.; writing-review andediting, C.A., L.N., G.S.-S., A.G., Y.W. and G.S. All authors have read and agreed to the published version of the manuscript.

Funding: This research did not receive any specific grant from funding agencies in the public, commercial, or not-for-profit sectors.

Conflicts of Interest: The authors have no conflict of interests to declare.

\section{References}

1. Von Haehling, S.; Arzt, M.; Doehner, W.; Edelmann, F.; Evertz, R.; Ebner, N.; Herrmann-Lingen, C.; Macedo, T.G.; Koziolek, M.; Noutsias, M.; et al. Improving exercise capacity and quality of life using non-invasive heart failure treatments: Evidence from clinical trials. Eur. J. Hear. Fail. 2020. [CrossRef] [PubMed]

2. Schmidt, C.; Moreira-Gonçalves, D.; Santos, M.; Leite-Moreira, A.; Oliveira, J. Physical activity and exercise training in heart failure with preserved ejection fraction: Gathering evidence from clinical and pre-clinical studies. Heart Fail. Rev. 2020, 1-14. [CrossRef]

3. Kurmani, S.; Squire, I. Acute Heart Failure: Definition, Classification and Epidemiology. Curr. Heart Fail. Rep. 2017, 14, 385-392. [CrossRef] [PubMed]

4. Dharmarajan, K.; Rich, M.W. Epidemiology, Pathophysiology, and Prognosis of Heart Failure in Older Adults. Heart Fail. Clin. 2017, 13, 417-426. [CrossRef]

5. Fried, L.P.; Tangen, C.M.; Walston, J.; Newman, A.B.; Hirsch, C.; Gottdiener, J.; Seeman, T.; Tracy, R.; Kop, W.J.; Burke, G.; et al. Frailty in older adults: Evidence for a phenotype. J. Gerontol. Ser. A Boil. Sci. Med. Sci. 2001, 56, M146-M157. [CrossRef]

6. Wilkinson, D.; Piasecki, M.; Atherton, P.J. The age-related loss of skeletal muscle mass and function: Measurement and physiology of muscle fibre atrophy and muscle fibre loss in humans. Ageing Res. Rev. 2018, 47, 123-132. [CrossRef]

7. Allen, S.C. Systemic Inflammation in the Genesis of Frailty and Sarcopenia: An Overview of the Preventative and Therapeutic Role of Exercise and the Potential for Drug Treatments. Geriatrics 2017, 2, 6. [CrossRef]

8. Dodson, J.A.; Chaudhry, S.I. Geriatric Conditions in Heart Failure. Curr. Cardiovasc. Risk Rep. 2012, 6, 404-410. [CrossRef]

9. Boxer, R.S.; Wang, Z.; Walsh, S.J.; Hager, D.; Kenny, A.M. The utility of the 6-minute walk test as a measure of frailty in older adults with heart failure. Am. J. Geriatr. Cardiol. 2008, 17, 7-12. [CrossRef]

10. Pascual, C.R.; Paredes-Galán, E.; Ferrero-Martínez, A.-I.; González-Guerrero, J.L.; Calvo, M.H.; Colino, R.M.; Torres-Torres, I.; Vilches-Moraga, A.; Galán, M.-C.; Suarez-Garcia, F.; et al. The frailty syndrome is associated with adverse health outcomes in very old patients with stable heart failure: A prospective study in six Spanish hospitals. Int. J. Cardiol. 2017, 236, 296-303. [CrossRef]

11. McNallan, S.M.; Chamberlain, A.M.; Gerber, Y.; Singh, M.; Kane, R.L.; Weston, S.A.; Dunlay, S.M.; Jiang, R.; Roger, V.L. Measuring frailty in heart failure: A community perspective. Am. Heart J. 2013, 166, 768-774. [CrossRef] [PubMed]

12. Madan, S.A.; Fida, N.; Barman, P.; Sims, D.; Shin, J.; Verghese, J.; Piña, I.; Jorde, U.; Patel, S.R. Frailty Assessment in Advanced Heart Failure. J. Card. Fail. 2016, 22, 840-844. [CrossRef] [PubMed]

13. Vidán, M.T.; Blaya-Novakova, V.; Sánchez, E.; Alonso, F.J.O.; Serra-Rexach, J.A.; Bueno, H. Prevalence and prognostic impact of frailty and its components in non-dependent elderly patients with heart failure. Eur. J. Heart Fail. 2016, 18, 869-875. [CrossRef] [PubMed]

14. Anani, S.; Goldhaber, G.; Brom, A.; Lasman, N.; Turpashvili, N.; Shenhav-Saltzman, G.; Avaky, C.; Negru, L.; Agbaria, M.; Ariam, S.; et al. Frailty and Sarcopenia Assessment upon Hospital Admission to Internal Medicine Predicts Length of Hospital Stay and Re-Admission: A Prospective Study of 980 Patients. J. Clin. Med. 2020, 9, 2659. [CrossRef]

15. Portal, D.; Hofstetter, L.; Eshed, I.; Lantsman, C.D.; Sella, T.; Urban, D.; Onn, A.; Bar, J.; Segal, G. L3 skeletal muscle index (L3SMI) is a surrogate marker of sarcopenia and frailty in non-small cell lung cancer patients. Cancer Manag. Res. 2019, 11, 2579-2588. [CrossRef] 
16. Vespasiani-Gentilucci, U.; De Vincentis, A.; Ferrucci, L.; Bandinelli, S.; Incalzi, R.A.; Picardi, A. Low Alanine Aminotransferase Levels in the Elderly Population: Frailty, Disability, Sarcopenia, and Reduced Survival. J. Gerontol. Ser. A Boil. Sci. Med. Sci. 2017, 73, 925-930. [CrossRef]

17. Irina, G.; Refaela, C.; Brom, A.; Avia, D.; Liron, H.; Chen, A.; Gad, S. Low Blood ALT Activity and High FRAIL Questionnaire Scores Correlate with Increased Mortality and with Each Other. A Prospective Study in the Internal Medicine Department. J. Clin. Med. 2018, 7, 386. [CrossRef]

18. Chung, S.M.; Moon, J.S.; Yoon, J.S.; Won, K.C.; Lee, H.W. Low alanine aminotransferase levels predict low muscle strength in older patients with diabetes: A nationwide cross-sectional study in Korea. Geriatr. Gerontol. Int. 2020, 20, 271-276. [CrossRef]

19. Lasman, N.; Shalom, M.; Turpashvili, N.; Goldhaber, G.; Lifshitz, Y.; Leibowitz, E.; Berger, G.; Saltzman-Shenhav, G.; Brom, A.; Cohen, D.; et al. Baseline low ALT activity is associated with increased long-term mortality after COPD exacerbations. BMC Pulm. Med. 2020, 20, 1-6. [CrossRef]

20. Itelman, E.; Segev, A.; Ahmead, L.; Leibowitz, E.; Agbaria, M.; Avaky, C.; Negro, L.; Shenhav-Saltzman, G.; Wasserstrum, Y.; Segal, G. Low ALT values amongst hospitalized patients are associated with increased risk of hypoglycemia and overall mortality: A retrospective, big-data analysis of 51831 patients. QJM Int. J. Med. 2020. [CrossRef]

21. Kashkosh, R.; Gringauz, I.; Weissmann, J.; Segal, G.; Swartzon, M.; Adunsky, A.; Justo, D. Prerehabilitation alanine aminotransferase blood levels and one-year mortality rates in older adults following hip fracture. Int. J. Rehabil. Res. 2020, 43. [CrossRef] [PubMed]

22. Ramaty, E.; Maor, E.; Peltz-Sinvani, N.; Brom, A.; Grinfeld, A.; Kivity, S.; Segev, S.; Sidi, Y.; Kessler, T.; Sela, B.; et al. Low ALT blood levels predict long-term all-cause mortality among adults. A historical prospective cohort study. Eur. J. Intern. Med. 2014, 25, 919-921. [CrossRef] [PubMed]

23. Kogan, M.; Klempfner, R.; Lotan, D.; Wasserstrum, Y.; Goldenberg, I.; Segal, G. Low ALT blood levels are associated with lower baseline fitness amongst participants of a cardiac rehabilitation program. J. Exerc. Sci. Fit. 2018, 16, 1-4. [CrossRef] [PubMed]

24. Irina, G.; Weismann, J.; Justo, D.; Adunsky, A.; Segal, G. Alanine aminotransferase blood levels and rehabilitation outcome in older adults following hip fracture surgery. Int. J. Rehabil. Res. 2018, 41, 41-46. [CrossRef]

25. Cioffi, G.; Dahlström, U.; Filippatos, G.; Chioncel, O.; Leiro, M.C.; Drozdz, J.; Fruhwald, F.; Gullestad, L.; Logeart, D.; Fabbri, G.; et al. EURObservationalResearch Programme: Regional differences and 1-year follow-up results of the Heart Failure Pilot Survey (ESC-HF Pilot). Eur. J. Heart Fail. 2013, 15, 808-817. [CrossRef]

26. Rich, M.W.; Chyun, D.A.; Skolnick, A.H.; Alexander, K.P.; Forman, D.E.; Kitzman, D.W.; Maurer, M.S.; McClurken, J.B.; Resnick, B.M.; Shen, W.K.; et al. Knowledge Gaps in Cardiovascular Care of the Older Adult Population. Circulation 2016, 133, 2103-2122. [CrossRef]

27. Jha, S.R.; Hannu, M.K.; Chang, S.; Montgomery, E.; Harkess, M.; Wilhelm, K.; Hayward, C.S.; Jabbour, A.; Spratt, P.M.; Newton, P.; et al. The Prevalence and Prognostic Significance of Frailty in Patients With Advanced Heart Failure Referred for Heart Transplantation. Transplantation 2016, 100, 429-436. [CrossRef]

28. Green, P.; Woglom, A.E.; Généreux, P.; Daneault, B.; Paradis, J.-M.; Schnell, S.; Hawkey, M.; Maurer, M.S.; Kirtane, A.J.; Kodali, S.; et al. The Impact of Frailty Status on Survival After Transcatheter Aortic Valve Replacement in Older Adults With Severe Aortic Stenosis. JACC Cardiovasc. Interv. 2012, 5, 974-981. [CrossRef]

29. Afilalo, J.; Lauck, S.; Kim, D.H.; Lefèvre, T.; Piazza, N.; Lachapelle, K.; Martucci, G.; Lamy, A.; Labinaz, M.; Peterson, M.D.; et al. Frailty in Older Adults Undergoing Aortic Valve Replacement. J. Am. Coll. Cardiol. 2017, 70, 689-700. [CrossRef]

30. Vidán, M.T.; Sánchez, E.; Ortiz, J.; Bueno, H.; Fernández-Avilés, F.; Serra-Rexach, J.A. FRAIL-HF, a Study to Evaluate the Clinical Complexity of Heart Failure in Nondependent Older Patients: Rationale, Methods and Baseline Characteristics. Clin. Cardiol. 2014, 37, 725-732. [CrossRef]

31. Yang, X.; Lupón, J.; Vidán, M.T.; Ferguson, C.; Gastelurrutia, P.; Newton, P.J.; Macdonald, P.S.; Bueno, H.; Bayés-Genís, A.; Woo, J.; et al. Impact of Frailty on Mortality and Hospitalization in Chronic Heart Failure: A Systematic Review and Meta-Analysis. J. Am. Heart Assoc. 2018, 7. [CrossRef] [PubMed]

32. Bellumkonda, L.; Tyrrell, D.J.; Hummel, S.L.; Goldstein, D.R. Pathophysiology of heart failure and frailty: A common inflammatory origin? Aging Cell 2017, 16, 444-450. [CrossRef] [PubMed] 
33. Mann, D.L. Innate immunity and the failing heart: The cytokine hypothesis revisited. Circ. Res. 2015, 116, 1254-1268. [CrossRef] [PubMed]

34. Molfino, A.; Anker, S.; Argiles, J.; Aversa, Z.; Bauer, J.; Biolo, G.; Boirie, Y.; Bosaeus, I.; Cederholm, T.; Costelli, P.; et al. Consensus definition of sarcopenia, cachexia and pre-cachexia: Joint document elaborated by Special Interest Groups (SIG) "cachexia-anorexia in chronic wasting diseases" and "nutrition in geriatrics". Clin. Nutr. 2010, 29, 154-159. [CrossRef]

35. Woo, J.; Leung, J.; Morley, J.E. Comparison of Frailty Indicators Based on Clinical Phenotype and the Multiple Deficit Approach in Predicting Mortality and Physical Limitation. J. Am. Geriatr. Soc. 2012, 60, 1478-1486. [CrossRef]

36. Turner, G.; Clegg, A.P. Best practice guidelines for the management of frailty: A British Geriatrics Society, Age UK and Royal College of General Practitioners report. Age Ageing 2014, 43, 744-747. [CrossRef]

37. Le Couteur, D.G.; Blyth, F.M.; Creasey, H.M.; Handelsman, D.J.; Naganathan, V.; Sambrook, P.N.; Seibel, M.J.; Waite, L.M.; Cumming, R.G. The Association of Alanine Transaminase With Aging, Frailty, and Mortality. J. Gerontol. Ser. A Boil. Sci. Med. Sci. 2010, 65A, 712-717. [CrossRef]

38. Peltz-Sinvani, N.; Klempfner, R.; Ramaty, E.; Sela, B.A.; Goldenberg, I.; Segal, G. Low ALT Levels Independently Associated with 22-Year All-Cause Mortality Among Coronary Heart Disease Patients. J. Gen. Intern. Med. 2015, 31, 209-214. [CrossRef]

39. Nam, J.-S.; Kim, W.-J.; An, S.-M.; Choi, D.-K.; Chin, J.-H.; Lee, E.-H.; Choi, I.-C. Age-dependent relationship between preoperative serum aminotransferase and mortality after cardiovascular surgery. Aging 2019, 11, 9060-9074. [CrossRef]

40. Nikolaou, M.; Parissis, J.; Yilmaz, M.B.; Seronde, M.-F.; Kivikko, M.; Laribi, S.; Paugam-Burtz, C.; Cai, D.; Pohjanjousi, P.; Laterre, P.-F.; et al. Liver function abnormalities, clinical profile, and outcome in acute decompensated heart failure. Eur. Heart J. 2012, 34, 742-749. [CrossRef]

41. Ponikowski, P.; Voors, A.A.; Anker, S.D.; Bueno, H.; Cleland, J.G.; Coats, A.J.S.; Falk, V.; González-Juanatey, J.R.; Harjola, V.-P.; Jankowska, E.; et al. 2016 ESC guidelines for the diagnosis and treatment of acute and chronic heart failure. Russ. J. Cardiol. 2017, 141, 7-81. [CrossRef]

42. Yancy, C.W.; Jessup, M.; Bozkurt, B.; Butler, J.; Casey, N.E.; Colvin, M.M.; Drazner, M.H.; Filippatos, G.S.; Fonarow, G.C.; Givertz, M.M.; et al. 2017 ACC/AHA/HFSA Focused Update of the 2013 ACCF/AHA Guideline for the Management of Heart Failure. J. Am. Coll. Cardiol. 2017, 70, 776-803. [CrossRef] [PubMed]

43. Morley, J.E.; Vellas, B.; Van Kan, G.A.; Anker, S.D.; Bauer, J.M.; Bernabei, R.; Cesari, M.; Chumlea, W.; Doehner, W.; Evans, J.; et al. Frailty consensus: A call to action. J. Am. Med. Dir. Assoc. 2013, 14, $392-397$. [CrossRef] [PubMed]

(C) 2020 by the authors. Licensee MDPI, Basel, Switzerland. This article is an open access article distributed under the terms and conditions of the Creative Commons Attribution (CC BY) license (http://creativecommons.org/licenses/by/4.0/). 